\title{
Postpartum Depression Screening: Importance, Methods, Barriers, and Recommendations for Practice
}

\author{
Dwenda K. Gjerdingen, MD, MS, and Barbara P. Yawn, MD, MSc
}

Background: Postpartum depression occurs in $10 \%$ to $20 \%$ of women who have recently given birth, but fewer than half of cases are recognized. The purpose of this review is to discuss the potential benefit of mass screening for improving postpartum depression recognition and outcomes.

Methods: A review of the literature was conducted by searching MEDLINE, using the key words "depression," "postpartum depression," and "mass screening." The Cochrane database was also searched for reviews on depression and postpartum depression.

Results: Opportunities for routine postpartum depression screening include mothers' postpartum office visits and their infants' well-child visits. Although several depression screens have been used in postpartum women, additional studies using large representative samples are needed to identify the ideal screening tool. Depression screening plus "high-risk" feedback to providers improves the recognition of depression. However, for screening to positively impact clinical outcomes, it needs to be combined with systems-based enhanced depression care that provides accurate diagnoses, strong collaborative relationships between primary care and mental health providers, and longitudinal case management, to assure appropriate treatment and follow-up.

Conclusions: Postpartum depression screening improves recognition of the disorder, but improvement in clinical outcomes requires enhanced care that ensures adequate treatment and follow-up. ( $\mathrm{J}$ Am Board Fam Med 2007;20:280-288.)

Depression is common and costly, particularly for women in their childbearing years. The World Health Organization has identified major depression as the fourth leading cause of burden among all diseases, and the leading cause of years lived with disability. ${ }^{1}$ It is estimated that depression costs the United States $\$ 30$ billion to $\$ 50$ billion in lost productivity and direct medical costs each year. ${ }^{2} \mathrm{By}$ 2020, depressive illness is expected to be the second leading cause of disability in the world. ${ }^{3}$ The burden is greatest for women, with a lifetime risk for major depressive disorder of $20 \%$ to $25 \%$, approximately twice the $7 \%$ to $12 \%$ rate seen with men. ${ }^{4}$

This article was externally peer reviewed.

Submitted 27 September 2006; revised 26 December 2006; accepted 4 January 2007.

From the Department of Family Medicine and Community Health, University of Minnesota, Minneapolis, MN (DKG); and Olmsted Medical Center, Rochester, MN (BPY).

Funding: none.

Conflict of interest: none declared.

Corresponding author: Dwenda K. Gjerdingen, MD, MS, Department of Family Medicine and Community Health, University of Minnesota-St. Joseph's Hospital Family Practice Residency Program, 580 Rice Street, St. Paul, MN 55103 (E-mail: dgjerdin@umphysicians.umn.edu).
In the first 3 months after childbirth, $14.5 \%$ of women have a new episode of major or minor depression, ${ }^{5}$ and $10 \%$ to $20 \%$ of mothers are believed to suffer with depression sometime during their postpartum course, ${ }^{6}$ making postpartum depression the most common serious postpartum disorder.

There is some controversy about whether rates of depression increase after delivery, and whether postpartum depression is a distinct entity from nonpostpartum depression. A British case-control study of mothers from 4 general practices found a 3 -fold higher incidence of depression within 5 weeks after childbirth. ${ }^{7}$ Similarly, a Norwegian study comparing postpartum with nonpostpartum women found a 1.8-fold greater risk for depression in postpartum women. ${ }^{8}$ However, other researchers have not found the risk of depression to be an higher in postpartum women, compared with other young women, suggesting that postpartum depression may not be a distinct condition but merely major depression recognized at a time of potential stress. ${ }^{7,9-15}$ Investigators have also looked for differences in natural history or recurrence rates that would suggest postpartum depression to be a 
unique condition. ${ }^{13}$ Studies looking for biochemical associates with postpartum depression such as thyroid antibodies ${ }^{12,16-18}$ are interesting but seem to identify only a small group of women who will develop postpartum depression. ${ }^{12}$ Estrogen and progesterone fluctuations have not been shown to predict or follow postpartum depression. ${ }^{12,19-21}$ Recent studies investigating a broader spectrum of hormones seem promising, ${ }^{22}$ but are unlikely to provide clinically useful biochemical screening or prediction tools for many years. Whether postpartum depression is a separate type of depression or simply an important time to identify depression in women may be of little practical importance.

The clinical presentation of postpartum depression is like that of other major depressive disorders, with symptoms of depressed mood, diminished pleasure, marked change in appetite and sleep, psychomotor agitation or retardation, fatigue, feelings of worthlessness or inappropriate guilt, decreased concentration, and recurrent thoughts of death or suicide. $^{23}$ The presence of maternal depressive symptoms at a critical time for infant and family has additional adverse effects, such as marital distress, ${ }^{24}$ problems with mother-infant interaction and attachment, ${ }^{25}$ and adverse behavioral and cognitive effects in the child. ${ }^{26}$ Although the Diagnostic and Statistical Manual of Mental Disorders (DSM-IV) specifies that the symptoms of postpartum depression must begin within 4 weeks after delivery, ${ }^{23}$ many experts believe that women remain at increased risk for depression for up to 1 year after delivery. ${ }^{5}$

Children of depressed mothers are more likely to have delayed psychological, cognitive, neurological, and motor development, and are at higher risk of avoidance and distressed behavior. ${ }^{27-29}$ In fact, depressed mothers, compared with nondepressed mothers, report a 3 -fold greater risk of serious emotional problems in their children and a 10-fold greater risk of having poor mother-child relations. ${ }^{30}$ The withdrawn, unresponsive, or negative behavior of a depressed mother early in the infant's life seems to affect maternal-infant attachment ${ }^{31}$ and result in fussier infants who vocalize less and make fewer positive facial expressions than infants of mothers who are not depressed. ${ }^{27,29,32-34}$ The abnormal patterns of mother-infant interactions associated with maternal depression have been described as a vicious cycle that increases the likelihood of chronic mental health, emotional, and family function problems. ${ }^{35,36}$ Children's behavioral difficulties associated with maternal depression may continue through at least ages 4 to 8 years. ${ }^{37-40}$ In addition, these children tend to use more health care resources for a broad spectrum of concerns. $^{41,42}$ Fortunately, remission of maternal depression is associated with reductions in children's mental and behavioral disorders. ${ }^{43}$

Given the potentially serious consequences of postpartum depression, it is unfortunate that the rates of diagnosis and treatment of this serious problem are low, ${ }^{44-46}$ primarily because of lack of recognition. This paper focuses on the recognition of postpartum depression through depression screening, current screening practices and methodologies, and barriers to postpartum depression screening and treatment. Recommendations for postpartum depression screening and future research are presented.

\section{Methods}

Background for this review was performed by searching OVID/MEDLINE, using the terms "depression," "postpartum depression," "mass screening," and "preventive health services." The Cochrane database was searched for reviews on depression and postpartum depression, and evidence on a particular topic was summarized by a published systematic review, whenever possible.

\section{Results}

Findings from the literature on postpartum depression screening at postpartum and well-child visits, postpartum depression screening instruments, and barriers to screening and treatment are presented here. These results are synthesized to provide recommendations for practice.

\section{Depression Screening in General Populations}

The published data on patient outcomes with screening for postpartum depression are limited; therefore, it is useful to review results for depression screening in general populations. In 2002, the US Preventive Services Task Force recommended routine depression screening for adults seen in practices that have systems in place to assure accurate diagnosis, effective treatment, and follow-up. ${ }^{47}$ This B-level recommendation was based on a review of 14 randomized controlled trials on depression screening in primary care. Screening with 
feedback to primary care physicians increased recognition of depression 2- to 3-fold, but did not always improve patient outcomes. Studies that included screening plus collaborative or enhanced care directed at diagnosis, treatment, and follow-up showed more positive patient outcomes. ${ }^{3}$

A subsequent Cochrane review reaffirmed these findings. ${ }^{48}$ This review included 12 trials (9 of which had been discussed in an earlier review), ${ }^{3}$ and a total of 5693 patients from nonmental health settings. Excluded from the review were trials with any modifications to usual care except screening. Screening/case finding instruments slightly improved the recognition of depression by clinicians [risk ratio (RR) 1.38 ; $95 \%$ CI 1.04 to 1.83 ]. Case recognition improved to a greater degree when clinicians were specifically informed of patients' positive screens (RR 2.66; 95\% CI 1.78 to 3.96). Unfortunately, the rate of intervention for recognized depression (eg, prescription of antidepressants) was not significantly different even with feedback (RR 1.35 ; $95 \%$ CI 0.98 to 1.85 ), and 3 of 4 studies reported no clinical effect of screening at either 6 or 12 months. ${ }^{48}$

Therefore, primary care research has demonstrated that depression screening alone does not greatly impact outcomes. However, depression recognition is enhanced when results of positive screens are communicated to providers, and clinical outcomes seem improved when depression screening and feedback programs are coupled with systems that ensure accurate diagnosis and effective treatment and follow-up. ${ }^{3}$ Such systems require trained health professionals and office staff, collaborative working relationships between primary care and mental health providers, and case management that ensures regular follow-up and treatment compliance.

\section{Depression Screening in Postpartum Women}

Studies that have addressed postpartum depression screening demonstrate that screening is feasible in the outpatient setting and can improve the rates of detection and treatment. ${ }^{44-46,49-51}$ In addition, 2 large studies $(\mathrm{n}=860,479)$ found that the vast majority of mothers (more than $80 \%$ ) were comfortable with the idea of being screened for postpartum depression. ${ }^{52,53}$ However, the rate of current screening in primary care practices is below $50 \%$ by even the most optimistic estimates. ${ }^{54-56} \mathrm{~A}$ survey of members of the Washington Academy of
Family Physicians showed that postpartum depression was considered common, serious, and treatable. Seventy percent $(n=254)$ of family physicians said that they always or often screened for postpartum depression at the postpartum examination, while $46 \%$ did so at well-child checkups. However, only approximately $22 \%$ overall reported using a validated tool for screening, indicating that the majority of providers who said that they screened for postpartum depression did so with either unvalidated tools or informal assessments. ${ }^{55}$ Several studies have confirmed that informal or no assessment of potential postpartum depression is ineffective, resulting in fewer than half of cases or potential cases discovered through formal screening. ${ }^{44-46,51}$

For clinicians who do screen for depression, the results are not always used for further documented assessment or treatment. ${ }^{44,54,56}$ One study reported that only $23 \%$ of women with abnormal screening for depression or substance abuse had documentation of further evaluation or treatment, ${ }^{54}$ while another study found that $60 \%$ of screen-positive women had follow-up depression evaluations and $35 \%$ were reportedly treated. ${ }^{44}$ Therefore, even when providers routinely screen for postpartum depression with validated instruments, they do not always seem to use that information to guide clinical practice.

Failing a depression screening test should not be equated with having the condition, as only $50 \%$ of those with a positive screen actually have postpartum depression, depending on the test and cutoff score used. ${ }^{48}$ Diagnostic evaluation should always follow screening to confirm the diagnosis. ${ }^{57,58}$

\section{Postpartum Depression Screening Opportunities}

There are 2 convenient venues for routine depression screening in postpartum populations: mothers' postpartum office visits and their infants' well-child visits. Although postpartum visits are generally conducted by obstetricians, family physicians, and nurse midwives, well-child visits are usually performed by pediatricians and family physicians$79 \%$ and $19 \%$, respectively. ${ }^{59}$

\section{Postpartum Visits}

Postpartum depression screening at postpartum visits was studied in the primarily Caucasian population of Olmsted County, Minn. Routine screening for postpartum depression with a validated in- 
strument, the Edinburgh Postnatal Depression Scale (EPDS), increased the rate of diagnosis of postpartum depression from $3.7 \%$ before screening to $10.7 \%$ post screening, with $19.8 \%$ of women having an abnormal screening test. ${ }^{44}$ Treatment rates for postpartum depression also increased after the institution of formal routine screening. ${ }^{44,60,61}$ In another study of primarily Caucasian women from the United Kingdom, 17\% (30 of 176) had positive EPDS screens (score $\geq 12$ ), but only $7 \%$ were perceived to be depressed by the primary health care team. ${ }^{46}$

Higher rates of depression may be seen in lowincome or ethnically diverse populations. A study of North Carolina women, $78 \%$ of whom received Medicaid, reported an increase in postpartum depression from $6.3 \%$ before routine formal screening to $35.4 \%$ using the EPDS and diagnostic evaluation. ${ }^{45}$ Another study of mostly Hispanic and black mothers from 2 inner city practices found $22 \%$ (27 of 121 ) of women to have positive EPDS screens, but without use of the screening tool, providers believed that only $13 \%$ of mothers were at risk for depression. ${ }^{49}$

One study conducted depression screening both at 28 to 32 weeks gestation and then again at 6 weeks postpartum. Of the 4038 women who were screened prenatally, $11.1 \%$ were positive (EPDS $\geq 12$ ), and of the 520 screened after delivery, $7.3 \%$ were positive. The investigators of this study found that, because obstetrician/gynecologists were not comfortable diagnosing and treating depression, they had difficulty implementing postpartum depression screening until a system of referral and support was in place. $^{62}$

\section{Well-Child Visits}

Well-child visits provide a convenient longitudinal opportunity to screen for postpartum depression, as they occur at regular intervals throughout the first postpartum year. As with postpartum visits, screening for maternal depression during well-child visits improves the rate of depressive symptom detection, from $1.6 \%$ to $8.5 \%$ in 1 study, ${ }^{50}$ and from $29 \%$ to $40 \%$ in another. ${ }^{51}$ Although experts have long advocated screening for postpartum depression in the pediatric setting, ${ }^{63-65}$ most pediatric providers do not systematically do so, as evidenced by findings from the National Survey on Early Childhood Health, whereas $86.1 \%$ of the 2068 parents sur- veyed indicated that they had not, but should have been asked about family or psychosocial risks. ${ }^{66}$

Providers' reluctance to screen for postpartum depression is probably due to several factors, key among them being lack of training and experience. In a national survey of pediatricians, $57 \%$ said that they felt responsible for recognizing maternal depression, but only $32 \%$ expressed confidence in their ability to diagnose postpartum depression. ${ }^{58}$ In another nationwide sample of general pediatricians, $49 \%$ reported little or no education on postpartum depression, and a vast majority were unfamiliar with screening tools. Less than one third of these pediatricians believed that they would recognize postpartum depression. ${ }^{67}$ Although family physicians have training and experience with patients of all ages, less than one half (46\%) of those surveyed in the state of Washington said that they always or often screened mothers for postpartum depression during well-child visits, ${ }^{55}$ suggesting that factors other than training and experience contribute to physicians' reluctance to screen for postpartum depression.

Other factors that compromise physicians' recognition and management of postpartum depression are the lack of time to obtain adequate history and to educate and counsel patients. ${ }^{58}$ This can be particularly challenging during well-child visits, when physicians are already expected to obtain expansive histories and provide anticipatory guidance around numerous health and developmental topics. Pediatricians face additional challenges, as they do not typically care for adults, and therefore are not as equipped to manage adult mental health treatment and referral. Further, given that the depressed parent is not usually under the care of the pediatrician, the provider may feel awkward and perhaps legally vulnerable at the prospect of being involved in the mother's mental health care, particularly if the mother is suicidal.

Parents and clinicians seem to agree that recognizing and dealing with postpartum depression is important in the context of primary care of the infant. However, clinicians need to be educated regarding the potential value of screening for postpartum depression during well-child visits, methods for doing so, and strategies for developing systems to manage or refer women with positive screens. Clinicians also need to be reassured that 
their participation in postpartum depression diagnosis and care will not have legal repercussions.

\section{Postpartum Depression Screening Instruments}

Three separate systematic reviews have been recently performed to evaluate screening tools for postpartum depression, used either in the prenatal or postpartum period. In the first review, 16 studies that used instruments prenatally to identify women who may be "at risk" for postpartum depression were included. ${ }^{68}$ Although $16 \%$ to $52 \%$ of women in the 2 largest studies screened positive, only $8 \%$ to $35 \%$ of these identified women actually developed postpartum depression. Only 4 of the 16 studies had adequate sample sizes $(\mathrm{n}>1300$, assuming a postpartum depression prevalence of $13 \%$ ) to assess the sensitivity and specificity of postpartum depression screens. Two additional problems noted were not having validated screens on separate samples (true of 4 of 6 studies with sample sizes greater than 400), and between-study variability in cutoff scores, particularly with the EPDS. The authors concluded that no screening instruments were appropriate for prenatal prediction of postpartum postpartum depression. ${ }^{68}$ Although this review addressed the prenatal use of scales for predicting postpartum depression, these same concerns may also be applicable to postpartum screening for postpartum depression.

A second review looked at 36 studies of postpartum depression screens that met the criteria of a self report measure to assess depressive symptoms after 2 weeks postpartum, with published psychometric data on postpartum women. ${ }^{69}$ Eight instruments were evaluated: the Beck Depression Inventory (BDI) and BDI-II, (Bromley Postnatal Depression Scale (BPDS), Center for Epidemiologic Studies Depression Scale (CES-D), Clinical Interview Schedule (CIS), Diagnostic Interview Schedule (DIS), Edinburgh Postnatal Depression Scale (EPDS), General Health Questionnaire (GHQ), Inventory of Depressive Symptomatology (IDS), postpartum depression Screening Scale (PDSS), and Zung Self-Rating Depression Scale (Zung SDS). Results of this review suggest that the EPDS is the most extensively studied postpartum measure with moderate psychometric soundness. However, most of the studies included in this review had small sample sizes, with only 6 studies including more than 400 participants, and none reaching or exceeding the sample size of 1300 participants recommended by Austin and Lumley. ${ }^{68}$

A third review was conducted by the Agency for Healthcare Research and Quality and the Safe Motherhood Group, to determine in part the accuracy of different screening tools for detecting depression during the perinatal period. ${ }^{5}$ Ten studies reporting test characteristics for English-language screens were reviewed (6 of the studies had been included in the second review discussed earlier, but none had been included in the first). Again, the sample sizes were typically small (only 2 had sample sizes greater than 400), and external validity was often poor to fair (eg, most participants were white). For each of the depression screens-EPDS, BDI and BDI-II, PDSS, and CES-D—specificities were high, but sensitivities were variable. Although the EPDS and the PDSS seemed to have higher sensitivities than the BDI (with estimates ranging from 0.75 to 1.0 at different thresholds), it is difficult to know whether these are completely accurate, given the wide CIs and small sample sizes in several studies. It was recommended that future studies on perinatal depression screens must be designed with adequate sample sizes and should provide a more representative racial and ethnic mix. ${ }^{5}$

A newer screening tool that has gained popularity in studies on general depression, but has not yet been adequately studied in postpartum depression, is the Patient Health Questionnaire, 9-item depression module (PHQ-9), which consists of the actual criteria on which the diagnosis of major depression is based. Because of its brevity, relatively high positive predictive value $55 \%$ in primary care settings), and ability to provide information about both diagnostic criteria and depression severity, the PHQ-9 is thought by some to be the "best available depression screening tool for primary care." ${ }^{70} \mathrm{Al}$ though there are no readily available published reports on the validity of the PHQ-9 in screening for postpartum depression, the PHQ-9 has been effectively used as a screen in obstetrics/gynecology practices that include both women of childbearing age and older women. ${ }^{71}$ The 2-question screen, consisting of the first 2 questions of the PHQ-9 (regarding mood and pleasure), has been advocated as a quick screen. It was studied on 6000 patients in 8 primary care clinics and 7 obstetrical/gynecology clinics, where construct and criterion validity were found to be very good, and sensitivity and specific- 


\begin{tabular}{lcc}
\hline Recommendation & Level of Evidence & References \\
\hline $\begin{array}{l}\text { Adult patients should be routinely screened for depression in those } \\
\text { practices that have systems in place to assure accurate diagnosis, }\end{array}$ & B & 47 \\
effective treatment, and follow-up. & B & 5,69 \\
$\begin{array}{l}\text { The EPDS is the most extensively studied postpartum depression } \\
\text { screen, but no ideal postpartum depression screen has yet been } \\
\text { identified, and additional studies with representative, adequately } \\
\text { sized samples are recommended. }\end{array}$ & B & 44 to $46,49,50,51,60$ to 62 \\
$\begin{array}{l}\text { Screening for postpartum depression can be performed at } \\
\text { postpartum or well-child visits, with well-child visits providing } \\
\text { more screening opportunities. }\end{array}$ & \\
\hline
\end{tabular}

ity high ( $83 \%$ and $92 \%$, respectively). ${ }^{72}$ Some researchers recommend a 2 -stage screening process, whereby patients are initially screened with the 2-question screen, and those who respond positively to either or both questions are then given a longer instrument. ${ }^{70}$

Although several currently available depression screens have been used to identify postpartum depression in research and practice, additional studies with large, representative samples are needed to help identify the ideal postpartum depression screening tool. The "ideal" screening tool should be brief, inexpensive, easy to administer, possess a high sensitivity and good specificity, and contribute toward improved clinical outcomes. ${ }^{48}$

\section{Barriers and Opportunities}

Previous research on depression in primary care practices has identified 3 general types of barriers to effective depression diagnosis and treatment: patient-centered, physician-centered, and systems barriers. ${ }^{73}$ Patient-centered variables include cost and lack of insurance coverage, ${ }^{71,74-77}$ time constraints, ${ }^{71,77}$ social stigma, ${ }^{71,75}$ nonadherence to depression treatment, ${ }^{75}$ lack of follow-through with mental health referrals, ${ }^{75}$ and lack of access to care for various reasons. ${ }^{75}$ Physician centered variables include lack of time, ${ }^{58,74,76}$ managed care policies, ${ }^{74}$ competing demands, ${ }^{75}$ insufficient training/knowledge, ${ }^{58}$ insurance or payment problems, and fear of legal repercussions. Systems based variables also play a role and include infrequent follow-up visits for mothers, lack of objective, proactive monitoring of recovery, and separation of primary care and mental health services. ${ }^{75}$

In addition, mothers of infants may experience barriers that are unique to the postpartum or early child-rearing period, such as need for childcare during mental health visits, ${ }^{78}$ concern about med- ication effects on nursing infants, ${ }^{79}$ and fear of judgment and referral to child protection. ${ }^{80}$

Despite these numerous barriers, the opportunities afforded by postpartum depression screening and treatment are potentially vast and include not only improving the signs and symptoms of postpartum depression, but also enhancing the new mother's ability to parent, and her ability to continue to actively participate in a marriage or relationship. Recognizing and treating postpartum depression provides opportunities to decrease divorce rates, improve rates of normal child development and lower suicide and infanticide rates. ${ }^{26,28,40,81-86}$

\section{Summary and Recommendations}

In summary, postpartum depression is a serious problem that affects many mothers of infants. Although effective treatment is available, fewer than half of cases are recognized. Although mass screening-performed either at postpartum or well-child visits-would probably improve postpartum depression diagnosis rates, it may not impact clinical outcomes unless systems are in place to ensure effective treatment and follow-up. Studies using large, representative population bases are needed to identify a valid, efficient postpartum depression screen and to assess the impact of such a screen, together with enhanced care, on clinical maternal/ infant outcomes. Finally, we need to make every effort to reduce patient-, provider-, and systemsbased barriers to effective diagnosis and treatment of postpartum depression. Summary recommendations are presented in Table 1.

\section{References}

1. The World Health Report 2001: Mental Health: New Understanding, New Hope. Geneva: World Health Organization 2001, p. 30.

2. Robinson WD, Geske JA, Prest LA, Barnacle R. 
Depression treatment in primary care. J Am Board Fam Pract. 2005;18:79-86.

3. Pignone MP, Gaynes BN, Rushton JL, et al. Screening for depression in adults: a summary of the evidence for the U.S. Preventive Services Task Force. Ann Intern Med. 2002;136:765-76.

4. US Department of Health and Human Services. Depression in Primary Care: Volume I. Detection and Diagnosis. Depression Guideline Panel. Rockville, MD: Public Health Service, 1993.

5. Gaynes BN, Gavin N, Meltzer-Brody S, et al. Perinatal depression: prevalence, screening accuracy, and screening outcomes. Evidence Report/Technology Assessment No. 119. AHRQ Publication No. 05E006-2. Rockville, MD: Agency for Healthcare Research and Quality, February, 2005.

6. Steiner M. Perinatal mood disorders: position paper. Psychopharmacol Bull. 1998;34:301-6.

7. Cox JL, Murray D, Chapman G. A controlled study of the onset, duration and prevalence of postnatal depression. Br J Psychiatry. 1993;163:27-31.

8. Eberhard-Gran M, Tambs K, Opjordsmoen S, Skrondal A, Eskild A. A comparison of anxiety and depressive symptomatology in postpartum and nonpostpartum mothers. Soc Psychiatry Psychiatr Epidemiol. 2003;38:551-6.

9. Wickberg B, Hwang CP. Screening for postnatal depression in a population-based Swedish sample. Acta Psychiatr Scan. 1997;95:62-6.

10. O'Hara MW, Zekoski EM, Philipps LH, Wright EJ. Controlled prospective study of postpartum mood disorders: comparison of childbearing and nonchildbearing women. J Abnormal Psychol. 1990;99:3-15.

11. O'Hara MW, Schlechte JA, Lewis DA, et al. Prospective study of postpartum blues. Arch Gen Psych. 1991;48:801-6.

12. Harris B. Biological and hormonal aspects of postpartum depressed mood working towards strategies for prophylaxis and treatment. Br J Psych. 1994;164: 288-92.

13. Cooper PJ, Murray L. Course and recurrence of postnatal depression: evidence for the specificity of the diagnostic concept. Br J Psych. 1995;166:191-5.

14. Kumar R. Postnatal mental illness: a transcultural perspective. Soc Psychiatry Psychiatr Epidemiol. 1994;29:250-64.

15. Murray L, Stein A. The effects of postnatal depression on the infant. Baillieres Clin Obstet Gynaecol. 1989;3:921-33.

16. Harris B, Othman S, Davies JA, et al. Association between postpartum thyroid dysfunction and thyroid antibodies and depression. $\mathrm{Br}$ Med J. 1992;305:152-6.

17. Pop VJ, de Rooy HA, Vader HL, et al.[title] Postpartum thyroid dysfunction and depression in an unselected population. N Engl J Med. 1991;324(25): 1815-6. Erratum in: N Engl J Med. 1991;325(5): 371.
18. Prentice LM, Phillips DI, Sarsero D, et al. Geographical distribution of subclinical autoimmune thyroid disease in Britain: a study using highly sensitive direct assays for autoantibodies to thryoglobulin and thyroid peroxidase. Acta Endocrinol. 1990; 123:493-8.

19. Dalton K. Successful prophylactic progesterone for idiopathic postnatal depression. Int J Prenatal Perinatal Studies. 1989;323-7.

20. Henderson AF, Gregoire AJ, Kumar RD, Studd JW. Treatment to severe postnatal depression with oestradiol skin patches. Br J Psychiatry. 1991;338(8770): 816-7.

21. Feksi A, Harris B, Walker RF, Riad-Fahmy D, Newcombe RG. "Maternity blues" and hormone levels in saliva. J Aff Disorders. 1984;6:355-6.

22. Bloch M, Schmidt PJ, Danaceau M, et al. Effects of gonadal steroids in women with a history of postpartum depression. Am J Psychiatry. 2000;157:924-30.

23. American Psychiatric Association: Diagnostic and Statistical Manual of Mental Disorders, 4th ed. (DSM-IV). Washington, DC: American Psychiatric Association, 2000.

24. Beck CT. Predictors of postpartum depression. Nurs Res. 2001;50:275-85.

25. Righetti-Veltema M, Bousquet A, Manzano J. Impact of postpartum depressive symptoms on mother and her 18-mont-old infant. European Child Adolescent Psychiatry. 2003;12:75-83.

26. Grace SL, Evindar A, Stewart DE. The effect of postpartum depression on child cognitive development and behavior: a review and critical analysis of the literature. Arch Women's Mental Health. 2003; 6:263-74.

27. Field T. Infants of depressed mothers. Infant Behav Dev. 1995;18:1-13.

28. Tronick E, Weinberg K. Depressed mothers and infants: failure to form dyadic states of consciousness. In: Murray L, Cooper P, editors. Postpartum Depression and Child Development. New York: The Guilford Press; 1997.

29. Abrams SM, Field T, Scafidi F, Prodromidis M. Newborns of depressed mothers. Infant Mental Health. J 1995;16:233-9.

30. Weissman MM, Feder A, Pilowsky DJ, et al. Depressed mothers coming to primary care: maternal reports of problems with their children. J Aff Disorders. 2004;78:93-100.

31. Murray L. The impact of postnatal depression on infant development. J Child Psychol Psychiatry. 1992;33:543-61.

32. Field T, Healy B, Goldstein S, et al. Infants of depressed mothers show "depressed" behavior even with nondepressed adults. Child Dev. 1988;59:1569-79.

33. Stein A, Gath DH, Bucher J, et al. The relationship between postnatal depression and mother-child interaction. Br J Psychiatry. 1991;158:46-52. 
34. Cramer B. Are postpartum depressions a motherinfant relationship disorder? Infant Mental Health J. 1993;14:283-97.

35. Guedeney N. A propos des meres deprimees: 1;impact de la depression sur les interactions precoces: revue de litterature anglosaxonne. Annales de Pediatrie. 1993;40:496-502.

36. Frodi A, Bridges L, Shonk S. Maternal correlates of infant temperament ratings and of infant-mother attachment: a longitudinal study. Infant Mental Health J. 1989;10:273-89.

37. Rotnem DL. An examination of the association between maternal depression and the behavioral functioning of school-age children. [dissertation]. Northampton (MA): Smith College School for Social Work, 1991. Dissertation Abstracts International. 1991;52(1-B): 156 .

38. Murray L, Cooper P. The role of infant and maternal factors in postpartum depression, mother-infant interactions, and infant outcome. In: Murray L, Cooper PJ, editors. Postpartum Depression and Child Development. New York: The Guilford Press; 1997.

39. Murray L, Fiori-Cowley A, Hooper R, Cooper P. The impact of postnatal depression and associated adversity on early mother-infant interactions and later infant outcome. Child Dev. 1996;67:2512-52.

40. Beck, CT. The effects of postpartum depression on child development: a meta-analysis. Arch Psychiatr Nurs. 1998;12:12-20.

41. Wolkind S. Mothers' depression and their children's attendance at medical facilities. J Psychosom Res. 1985;29:579-82.

42. Kolter T, Buzwell S. Romeo Y, Bowland J. Avoidant attachment as a risk factor for health. Br J Med Psych. 1994;67:237-45.

43. Weissman MM, Pilowsky DJ, Wickramaratne PJ, et al. Remissions in maternal depression and child psychopathology. A STAR*D-Child Report. JAMA. 2006;295:1389-98.

44. Georgiopoulos AM, Bryan TL, Wollan P, Yawn BP. Routine screening for postpartum depression. J Fam Pract. 2001;50:117-22.

45. Evins GG, Theofrasstous JP, Galvin SL. Postpartum depression: a comparison of screening and routine clinical evaluation. Am J Obstet Gynecol. 2000;182: 1080-2.

46. Hearn G, Iliff A, Jones I, et al. Postnatal depression in the community. Br J Gen Pract. 1998;48:106466.

47. US Preventive Services Task Force. Screening for depression: recommendations and rationale. Ann Intern Med. 2002;136:760-4.

48. Gilbody S, House AO, Sheldon TA. Screening and case finding instruments for depression. The Cochrane Database of Systematic Reviews 2005, Issue 4. Art. No. CD002792.pub2.

49. Morris-Rush JK, Freda MC, Bernstein PS. Screen- ing for postpartum depression in an inner-city population. Am J Obstet Gynecol. 2003;188:1217-9.

50. Chaudron LH, Szilagyi PG, Kitzman HJ, Wadkins HIM, Conwell Y. Detection of postpartum depressive symptoms by screening at well-child visits. Pediatrics. 2004;113:551-8.

51. Heneghan AM, Silver EJ, Bauman LJ, Stein REK. Do pediatricians recognize mothers with depressive symptoms? Pediatrics. 2000;106:1367-73.

52. Buist A, Condon J, Brooks J, et al. Acceptability of routine screening for perinatal depression. J Aff Disorders. 2006;93:233-7.

53. Gemmill AW, Leigh B, Ericksen J, Milgrom J. A survey of the clinical acceptability of screening for postnatal depression in depressed and non-depressed women. BMC Pub Health. 2006;6:211.

54. Kelly BD. St John's wort for depression: what's the evidence?. Hosp Med. 2001;62:274-6.

55. Seehusen DA, Baldwin LM, Runkle GP, Clark G. Are family physicians appropriately screening for postpartum depression? J Am Board Fam Med. 2005; 18:104-12.

56. Spitzer RL, Kroenke K, Williams JBW, et al. Validation and utility of a self-report version of PRIMEMD: The PHQ primary care study. JAMA. 1999; 282:1737-44.

57. Yawn BP. Postpartum Depression, Part 1: Prevalence and Considerations in Screening. The Female Patient. 2006;31:37-42.

58. Olson AL, Kemper KJ, Kelleher KJ, Hammond CS, Zuckerman BS, Dietrich AJ. Primary care pediatricians' roles and perceived responsibilities in the identification and management of maternal depression. Pediatrics. 2002;110:1169-76.

59. Guirguis-Blake J, Fryer GE, Deutchman M, Green LA, Dovey SM, Phillips RL. Family physicians increase provision of well-infant care despite decline in prenatal services. Am Fam Physician. 2003;67:17.

60. Georgiopoulos AM, Bryan TL, Yawn BP, Houston MS, Rummans TA, Therneau TM. Populationbased screening for postpartum depression. Obstet Gynecol. 1999;93:653-7.

61. Bryan TL, Georgiopoulos AM, Harms RW. Huxsahl JE, Larson DR, Yawn BP. Incidence of postpartum depression in Olmsted County, Minnesota. A population-based, retrospective study. J Reprod Med. 1999;44:351-8.

62. Gordon TE, Cardone IA, Kim JJ, Gordon SM, Silver RK. Universal perinatal depression screening in an Academic Medical Center. Obstet Gynecol. 2006; 107:342-7.

63. Green M, ed. Bright Futures: Guidelines for Health Supervision of Infants, Children, and Adolescents. Arlington (VA): National Center for Education in Maternal and Child Health; 1994.

64. Freeman MP, Wright R, Watchman M, et al. Postpartum depression assessments at well-baby visits: 
screening feasibility, prevalence, and risk factors. J Womens Health. 2005;14:929-35.

65. Currie ML, Rademacher R. The pediatrician's role in recognizing and intervening in postpartum depression. Pediatr Clin North Am. 2004;51:785-801.

66. Bethell C, Reuland CHP, Halfon N, Schor EL. Measuring the quality of preventive and developmental services for young children: national estimates and patterns of clinicians' performance. Pediatrics. 2004;113:1973-83.

67. Wiley CC, Burke GS, Gill PA, Law NE. Pediatricians' views of postpartum depression: a self-administered survey. Arch Womens Mental Health. 2004; 7:231-6.

68. Austin MP, Lumley J. Antenatal screening for postnatal depression: a systematic review. Acta Psychiatr Scand. 2003;107:10-17.

69. Boyd RC, Le HN, Somberg R. Review of screening instruments for postpartum depression. Arch Womens Ment Health. 2005;8:141-53.

70. Nease DE, Malouin JM. Depression screening: a practical strategy. J Fam Pract. 2003;52:118-26.

71. Scholle SH, Haskett RF, Janusa BH, Pincus HA, Kupfer DJ. Addressing depression in obstetrics/ gynecology practice. Gen Hosp Psychiatry. 2003;25: 83-90.

72. Kroenke K, Spitzer RL, Williams JBW. The Patient Health Questionnaire-2. Validity of a two-item depression screener. Med Care. 2003;41:1284-92.

73. Nutting PA, Rost K, Dickinson M, et al. Barriers to initiating depression treatment in primary care practice. J Gen Intern Med. 2002;17:103-11.

74. Anonymous. Strategies for effective management of depression in primary care. Based on a presentation by Michael S. Klinkman, MD. Am J Man Care. 1999;5(13 Suppl):S783-8; discussion S788-93.

75. Katon WJ, Ludman EJ. Improving services for women with depression in primary care settings. Psychol Women Quarterly. 2003;27:114-20.
76. Williams JW, Rost K, Dietrich AJ, Ciotti MC, Zyzanski SJ. Primary care physicians' approach to depressive disorders. Arch Fam Med. 1999;8:58-67.

77. LaRocco-Cockburn A, Melville J, Bell M, Katon W. Depression screening attitudes and practices among obstetrician-gynecologists. Obstet Gynecol. 2003; 101:892-8.

78. Ugarriza DN. Group therapy and its barriers for women suffering from postpartum depression. Arch Psychiatr. Nurs. 2004;18:39-48.

79. Gjerdingen D. The effectiveness of various postpartum depression treatments and the impact of antidepressant drugs on nursing infants. J Am Board Fam Pract. 2003;16:372-82.

80. Heneghan AM, Mercer MB, Deleone NL. Will mothers discuss parenting stress and depressive symptoms with their child's pediatrician? Pediatrics. 2004;113:460-7.

81. Field T. Maternal depression effects on infants and early interventions. Prev Med. 1998;27:200-3.

82. Murray L, Sinclair D, Cooper P, et al. The socioemotional development of 5-year-old children of postnatally depressed mothers. J Child Psychiatry. 1999;40:1259-71.

83. Zelkowitz P, Milet TH. Screening for post-partum depression in a community sample. Can J Psychiatry. $1995 ; 40: 80-6$

84. Wang SY, Chen CH, Chin CC, Lee SL. Impact of postpartum depression on the mother-infant couple. Birth. 2005;32:39-44.

85. Ramsay M, Gisel EG, McCusker J, Bellavance F, Platt R. Infant sucking ability, non-organic failure to thrive, maternal characteristics, and feeding practices: a prospective cohort study. Dev Med Child Neurol. 2002;44:405-14.

86. Hay DF, Pawlby S, Sharp D, et al. Intellectual problems shown by 11-year-old children whose mothers had postnatal depression. J Child Psychiatry. 2001; 42:871-89. 